TABle VI. Luminous RANGE OF OIL LAMPS

\begin{tabular}{|c|c|c|c|c|}
\hline & \multicolumn{2}{|c|}{$\begin{array}{l}\text { Luminous intensity } \\
\text { (cd) }\end{array}$} & \multirow{2}{*}{$\begin{array}{c}\text { Probable } \\
\text { luminous } \\
\text { range } \\
\text { (n.m.) }\end{array}$} & \\
\hline & Source & $\begin{array}{c}\text { Source/ } \\
\text { lens/filter } \\
\text { combination }\end{array}$ & & \\
\hline $\begin{array}{l}\text { Side lights and 'not } \\
\text { under command' } \\
\text { Masthead lights }\end{array}$ & 12 & $\begin{array}{r}2 \cdot 4 \\
24 \cdot 0\end{array}$ & $\begin{array}{l}1 \frac{1}{2} \\
3 \frac{3}{4}\end{array}$ & $\begin{array}{c}\text { Based on a lens factor of } \times 2 \text { and } \\
\text { transmission factor of } 10 \%\end{array}$ \\
\hline $\begin{array}{l}\text { Red lights } \\
\text { Green lights } \\
\text { White lights }\end{array}$ & $\begin{array}{l}12 \\
12 \\
12\end{array}$ & $\begin{array}{r}7 \cdot 2 \\
5 \cdot 4 \\
36 \cdot 0\end{array}$ & $\begin{array}{l}2 \frac{1}{2} \\
2 \frac{1}{4} \\
4 \frac{1}{2}\end{array}$ & $\begin{array}{l}\text { Based on a lens factor of } \times 3 \text { and } \\
\text { filter transmission factor of } \\
20 \% \text { for red and } 15 \% \text { for } \\
\text { green }\end{array}$ \\
\hline
\end{tabular}

The first two items in Table VI show that such lights are apparently only suitable for the side lights of vessels up to 12 metres in length, and for stern or anchor lights for vessels of any length, under the new Collision Regulations. The other items apparently extend the use of coloured oil lights to vessels up to 50 metres in length, except as masthead lights for vessels 20 to 50 metres in length which are required to have a range of 5 miles. The alternative to oil lights would presumably be some form of battery operated electric light, in which case Table $\mathrm{V}$ provides some guidance as to the factors involved for voltages down to $24 \mathrm{~V}$.

\title{
A Tabular Method for Star-Sight Reduction
}

\section{Nastro and A. Russo}

IN a recent paper in this Journal the Director of the Royal Institute of Navigation describes some methods of navigating small vessels; he rightly includes classical astronomical navigation and describes some speedy and well-known methods of solution. In spite of the availability of such tables and mechanical devices the solution is not within everybody's reach because nautical ephemerides are always necessary; convenient tables are the Sight Reduction Tables for Air Navigation (A.P. 3270 ) from which the elements for tracing out the lines of position through the intercept method can easily be extracted. The simpler tables here proposed present the following advantages :

(i) the ephemeris is not required

(ii) the observed sextant altitude need not be corrected for refraction and dip.

Our tables are, however, valid for a limited sea area only; they are in fact ephemerides in which the altitude (corrected for astronomical refraction) and the azimuth of a few selected stars are given for an auxiliary point (the centre 
of the area) at every minute of time for the duration of nautical twilight. The area covered by our tables is between Sardinia and the Italian mainland, between latitudes $39^{\circ}$ and $4 \mathrm{I}^{\circ} \mathrm{N}$. and longitudes $10^{\circ}$ and $12^{\circ} \mathrm{E}$.

The tables are compiled for a determinate year (for example 1972) but they can be used for several years since an auxiliary table valid for a whole year supplies a correction that takes into account :

(i) the changes in the ephemeris from the adopted epoch to that of date

(ii) the dip correction valid for heights of eye up to 6 metres

(iii) the change in position of the body for interpolated seconds of time.

The observed altitude in degrees and minutes of arc and the observation time in hours, minutes, and seconds must be noted for each star. The azimuth and the altitude $h_{\mathrm{t}}$ are tabulated as functions of the time (day, hours and minutes of observation). The algebraic difference between $h_{0}$ (observed altitude) and $h_{\mathrm{t}}$ is indicated as $k_{1}$.

A corrective term $k_{2}$ is obtained from the auxiliary table which is entercd with the odd seconds of time (even if zero) and the azimuth. The algebraic sum of $k_{1}$ and $k_{2}$ gives the altitude intercept $\Delta h$.

The astronomical line of position is then traced on a special chart which embodies an azimuth protractor centred on the auxiliary point. The following example will serve to illustrate the method:

From a ship in D.R. position Lat. $39^{\circ} 24^{\prime}$ N., Long. $10^{\circ} 45^{\prime} \mathrm{E}$. (eastward of Sardinia), with true course $140^{\circ}$ and speed 6 knots during morning twilight of 7 July 1975 the following observations were effected:

$$
\begin{array}{lrl}
\text { Capella } & h_{0}=20^{\circ} 18^{\prime} \text { at } 4^{\mathrm{h}} 46^{\mathrm{m}_{\circ} 2^{\mathrm{s}}} \text { (summer time) } \\
\text { Fomalhaut } & 20^{\circ} 34^{\prime} \quad 4^{\mathrm{h}} 48^{\mathrm{m}_{12}} \\
\text { Vega } & 45^{\circ} 28^{\mathrm{s}} \quad 4^{\mathrm{h}} 50^{\mathrm{m}} \circ 0^{\mathrm{s}}
\end{array}
$$

The computations are:

$$
\begin{aligned}
& \text { Capella Fomalhaut Vega } \\
& h_{0}=20^{\circ} 18^{\prime} \quad h_{0}=20^{\circ} 34^{\prime} \quad h_{0}=45^{\circ} 28^{\prime} \\
& -h_{\mathrm{t}}=21^{\circ} \mathrm{II}^{\prime} \quad-h_{\mathrm{t}}=20^{\circ} 04^{\prime} \quad-h_{\mathrm{t}}=44^{\circ} 47^{\prime} \\
& k_{1}=-53^{\prime} \quad k_{1}=+30^{\prime} \quad k_{1}=+4 \mathrm{I}^{\prime} \\
& +k_{2}=+22^{\prime} \quad+k_{2}=-2^{\prime} \quad+k_{2}=-3^{\prime} \\
& \Delta h=-31^{\prime} \quad \Delta h=\overline{+28^{\prime}} \quad \Delta h=\overline{+5^{\prime}} \\
& \mathrm{Az}=047^{\circ} \quad \mathrm{Az}=175^{\circ} \quad \mathrm{Az}=289^{\circ}
\end{aligned}
$$

The lines of position are traced and the fix obtained is: Lat. $39^{\circ} 30^{\prime} \mathrm{N}$, , Long $10^{\circ} 40^{\prime} \mathrm{E}$. If the observations are made at different times the lines of position should be adjusted for the motion of the observer between observations. However if the ship's speed is not excessive and if the first star is abeam this adjustment is not necessary.

The proposed tables are known in Italy as Tavole RUNAS, but are not yet on sale. They have been used in the Tyrrhenian area on pleasure craft and small merchant ships. Similar tables for the Sun were computed for the Antarctic expedition in the Italian ship S. Giuseppe II. 
REFER EN C E

1 Richey, M. W. (1975). The navigation of small craft. This Journal, 28, 477.

\title{
D. H. Sadler comments
}

THE idea of an 'Altitude-Azimuth' almanac is not new though most effort (see this Journal, Vol. I, I 85, 1948; Vol. 2, 285, 1949) has been concerned with the Sun and planets rather than the stars. For the stars the simple problem is that observations are recorded in mean time (say G.M.T.) whereas the positions of the stars depend on sidereal time (L.H.A. Aries) given by: L.H.A. Aries = G.H.A. Aries + west longitude. A full account of star tables (and diagrams) using a mean-time argument (and thus avoiding using the Almanac to give G.H.A. Aries) is given in 'The Genesis of the E.A.N.T.s' (this Journal, Vol. 6, 333, 1953). Ignoring the complications arising from the motion of the observer between sights, and corrections for precession and nutation, there are innumerable methods of combining

(a) the observed mean time;

(b) a 'day' or 'year' correction to give the time-argument of the tables;

(c) corrections to altitude for non-tabular arguments ;

(d) interpolation in the tables;

(e) plotting from a fixed position, or from one whose longitude is chosen to avoid interpolation.

For world-wide use the choice depends on the planned usage and on the relative merits of simplicity in arithmetic or in plotting, as well as with material considerations of the size and cost of the tables.

The tables described above relate to a small range of longitude only and, taking advantage of the limited duration of twilight, can use G.M.T. directly as argument. This may not be the most economical method, but it is certainly simple for the user. The brief description does not include a discussion of the effect of the possible use of large intercepts, of the possible errors in refraction for low altitudes, and the incorporation of corrections for precession and nutation. These should be examined if the method is extended to larger areas and the tables are used for many years.

\section{A Position Line from an Object off the Chart}

\author{
Captain A. B Moody U.S.N.R.
}

THE use of the traverse table for plotting a bearing from an object outside the coverage area of the chart, as described by Pesi Sorab, 1 suggests a graphical solution that might be preferred by some navigators. The method is analogous to advancing a position line by advancing the position of the object observed.

Refer to Fig. 1. The bearing of an object off the northern limit of the chart is observed. Any convenient point on the chart is selected as the position of the fictitious object, and the reciprocal of the measured bearing is plotted from this 